\title{
Strategic Management and Decision Making of Small and Medium-Sized Enterprises in the Czech Republic
}

\author{
Jarmila Straková $^{1 *}$, Milan Talír ${ }^{1}$ \\ ${ }^{1}$ Institute of Technology and Business in České Budějovice, Faculty of Corporate Strategy, Okružní \\ 517/10, 37001 České Budějovice, Czech Republic
}

\begin{abstract}
The topic of strategic management and decision making was underestimated by SMEs for a long term. Managers believed that experience, intuition and operability are the key success factors of their management work. These opinions have recently been abandoned in the management practice. This paper is focused on the analysis of strategic management and decision making and presents the outputs from research based on a test sample of 381 enterprises, of which 114 microenterprises, 141 small enterprises and 126 medium-sized enterprises. The company size categorization within this sample is corresponding to the SME structure in the South Bohemian Region. Lack of awareness of procedures for development of essential strategic documents such as vision, mission statements and a corporate strategy was observed. More than $60 \%$ SMEs do not have such documents. are Similar results were obtained with respect to the development of a corporate strategy using the methods of a strategic situation analysis. This finding is alarming and its adverse impact can primarily be expected in a period of economic recession or downturn.

Key words: strategic management, vision, mission, corporate strategy, situation analysis
\end{abstract}

\section{Introduction}

Small and medium-sized enterprises (SMEs) in the Czech Republic have gone through a number of development stages. Year 1989 was a "crunch year" for implementation of strategic management and decision making elements into SME management systems. Transformation of the national economy was underway in that period of time, consisting in transition from centrally planned and closed economy to market oriented and open national economy. SMEs gradually changed to private ownership based businesses. The application of strategic management and decision making processes to SME corporate practice is limited by development of the strategic management science. It began to form at the end of the $60 \mathrm{~s}$ and at the beginning of the $70 \mathrm{~s}$ of the last century, in particular in the world advanced economies with developed market economy.

*Corresponding author: strakova@mail.vstecb.cz 
Porter [1], the guru of the global management science with Czech roots defines new categories in strategic management such as competitiveness, competitive advantage, competitive environment, and recently also the value chain. The key areas of successful small and medium-sized enterprises are characterized by the Peterson and Rondstadt concepts [2]. They define business success and prerequisites for business development using two factors - business know-how and know-who. Scientific analyses of local and foreign authors demonstrate that SMEs are unique as well as highly flexible [3-5]. Some authors concentrated on research of business as an activity using specific features of SME strategic potential and exploring the position of a business depending on its life cycle [6]. Many authors analyse the behaviour of entrepreneurs and the importance of personality traits of a manager with respect to SME, e.g. Birch [7] and Gunderson [8].

In the late 20th century, the issue of business success models in the SME environment was brought to the forefront of the international agenda [9]. The 90s of the last century are considered as a significant economic milestone in Europe. Both the world as well as European markets were saturated and businesses had to change the existing methods of management and planning. In the Czech Republic, the last decade of the last century is characterized by establishing SMEs in a new market environment at the national as well as international level. Their stabilization and transformation role, but also the high level of absorption in terms of engagement of workers gradually laid off by dissolved or ineffective operations are unique in Europe. More than 1 mil. workers found their jobs with SMEs, of which more than $60 \%$ in services.

The beginning of the 21 st century is characterized by dynamic and significant changes in the corporate environment. It is the period of time when the efficiency, stability and relationship with the external environment have become the priority for SMEs [10-11]. The dynamics of corporate resources then foster the business growth and sustainability and last but not least, they help to create competitive advantages in the business environment [1215]. All these authors apply the concept of competitive strategy by M. E. Porter and his five force analysis and the related publications of Gibbs [6], Lundström a Stevenson [16]. The current stage of development is characterized by the growing need for advanced management methods in SMEs and it is correct to say that the scientific platform does not always respond adequately.

Small and medium-sized enterprises in the Czech Republic mainly operate in rural areas, covering more than $70 \%$ of the Czech territory. The analysis of the SME and Sole Trader Association of the Czech Republic [17] shows a highly negative trend of business development in rural areas where more than $45 \%$ businesses are categorized as less developed. One of the tools that can considerably help to improve the economic situation of SMEs in general (and particularly for rural areas) is a modern management and administration concept where strategic management plays a key role.

\section{Data and Methods}

The research was conducted on a test sample of SMEs, in particular from the South Bohemian Region. The start of research dates back to 2016 and it is still ongoing. The sample includes 381 enterprises, of which 114 microenterprises, 141 small enterprises and 126 medium-sized enterprises. The size structure of this sample is corresponding to the SME structure in the South Bohemian Region.

Two hypotheses were created:

H1: Creating a SME vision and mission statement and corporate strategy is fully respected by the business sphere as a prerequisite for business stability and development.

H1: Situation analysis is widely used in the Czech business practice for projection of a corporate strategy and definition of development priorities. 
The Pearson's chi-squared test as a statistical method was used to measure dependence / independence of selected category variables (internal and external strategic analyses) in order to formulate a corporate strategy.

The formula for Pearson's chi-squared test of independence is as follows:

$$
\chi^{2}=\frac{\sum_{i=1}^{k}\left(X_{i}-N p_{i}\right)^{2}}{N p_{i}}
$$

$$
\begin{array}{ll}
\mathrm{X} 2 & \text { chi-square } \\
\mathrm{Xi} & \text { empirical frequency (actual) } \\
\mathrm{Npi} & \text { theoretical frequency (expected) }
\end{array}
$$

Our tests apply two hypotheses, null (H0) and alternative (HA). H0 (no dependence between selected variables), HA (dependence between selected variables). The evaluation criterion for verification or rejection of a hypothesis is $p$-value within the interval $<0.1>$. If the $\mathrm{p}$-value is $<\alpha$ (at the set significance level $\alpha=0.05$ ), HA will be confirmed. Statistical calculations were supported by the statistical program $\mathrm{R}$.

\section{Results}

The following conclusions are derived from the chart. The fact that the majority of enterprises/respondents developed their vision and mission statements and a long-term development plan (corporate strategy) was an unexpected but positive finding It is mainly surprising in case of microenterprises where given elements are created by the company owner or manager. However, a high rate (app 50\%) of them are not concerned with a longterm business plan which is a negative finding, especially for small and medium-size enterprises in view of the expected economic development. It was observed during a partial analysis and interviews that a strategic plan was elaborated on the tactical and operative level. As regards decomposition of strategic goals into tactical and operative objectives, strategic goals were found as highly prevailing in micro and small enterprises unlike small and medium-sized enterprises where strategic goals are slightly more decomposed into tactical objectives It can be explained by the characteristics of the relevant size categories of businesses. 


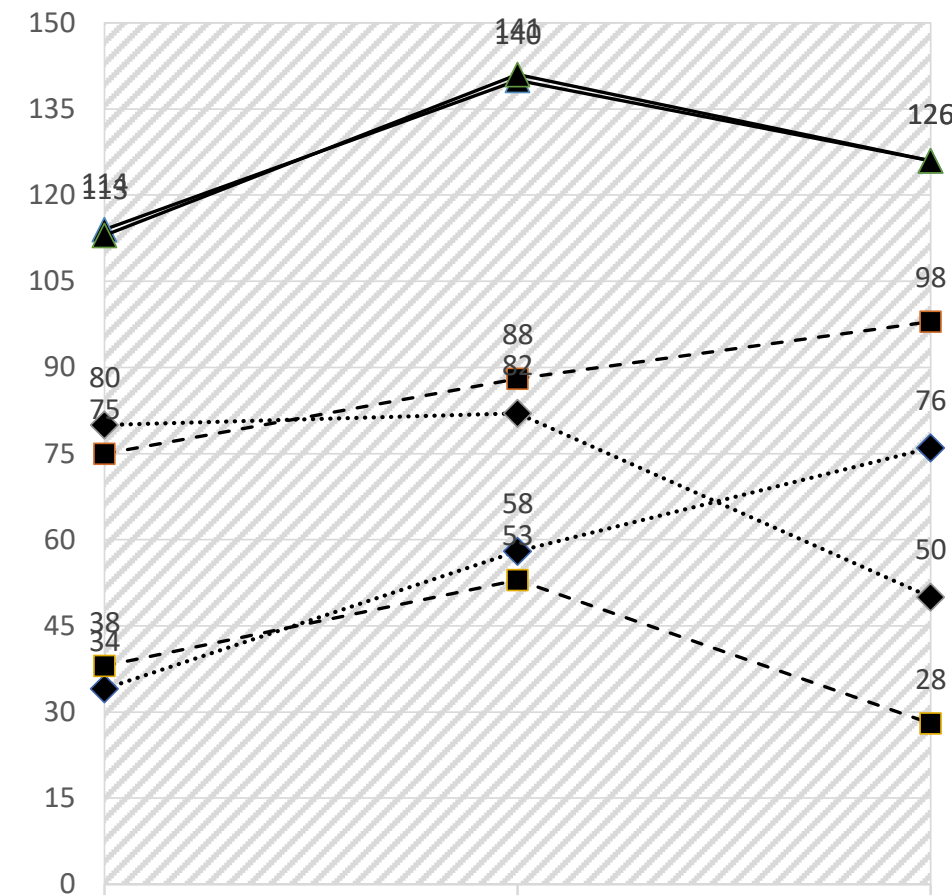

\section{Microenterprise (less than Small enterprise (less than Medium-sized enterprise 10 employees) $\quad 50$ employees) (50-249 employees)}
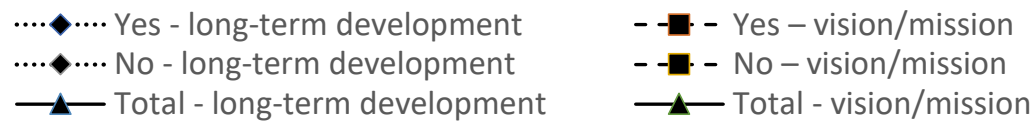

Fig. 1. Comparison of long-term development plan and vision/mission statements depending on the size of SME

Source: Own research.

Another research analysis was aimed at staffing for development of a strategic plan and partial departmental strategies in SMEs (see Chart 2). The development of a corporate strategy is mostly contributed by owners, namely for micro and small enterprises, or in some cases working together with the top management of medium-sized enterprises.

In the case of microenterprises, the owner is involved both in development of a corporate strategy and naturally also elaboration (decomposition) of such strategy into partial objectives.

In the case of small enterprises, owners are still highly involved in development of a corporate strategy while the entire top management team is more involved in development of a corporate strategy and the contribution of senior executives is slightly increasing. The decomposition of a corporate strategy into partial departmental strategies is still mostly contributed by the company owner followed by the entire top management team with slightly increased involvement of senior executives.

In the case of medium-sized enterprises, the situation regarding the development of a corporate strategy is quite different from the two categories above mentioned. A corporate 
strategy is mostly contributed by the entire top management team followed by the company owner and senior executives. For decomposition of a corporate strategy into partial departmental strategies, the key role is played by the entire top management, and the owner and senior executives then in equal parts. A significant dependence between the development of a corporate strategy and the company size category $(\alpha=0.05, \mathrm{p}=$ 0.003973 , chi-square $=11.0564, \mathrm{~V}=0.2492$ ) was confirmed across the test sample.

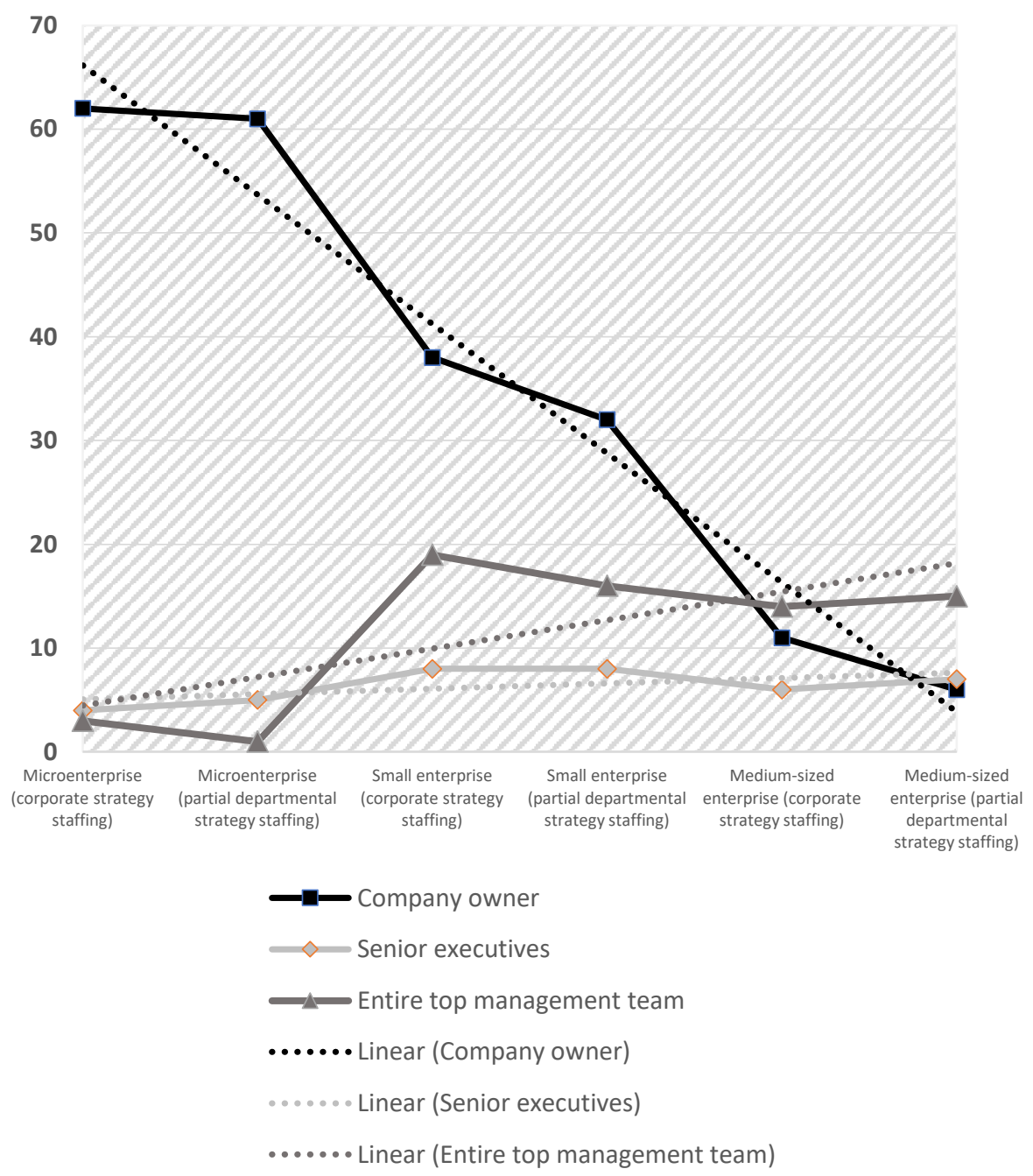

Fig. 2 Staffing for development of a corporate strategy and partial departmental strategies in SMEs Source: Own research.

The outputs as presented in the previous part are related to the solution of hypothesis 1 concerning the frequency of developing vision and mission statements and a corporate strategy and adherence to those documents by the company managers. This hypothesis is rejected based on the summary evaluation of results. The reason may be that more than half of the tested organizations do not create such documents and the supporting reasons are often based on very erroneous arguments contradictory to management principles. As an example, superiority of intuitive decision making to strategic thinking, in particular for 
microenterprises, or the declining importance of strategy in the turbulent and discontinuous world, etc.

The next part of this paper will explore the knowledge/awareness and use of situation analysis methods by the individual size categories and their application. The internal and external environment groups were analysed separately.

The following Chart 3 illustrates the use of internal analyses for the business environment. In the ascending order: GE model is least used, followed by an exposure analysis and SPACE analysis. On the contrary, a SWOT analysis, portfolio analysis and the analysis of internal resources of an organization analyses are most frequently used. The negative result is the fact that more than $60 \%$ companies do not have sufficient knowledge of the above analyses; it is a very negative finding especially for the category of mediumsized enterprises.

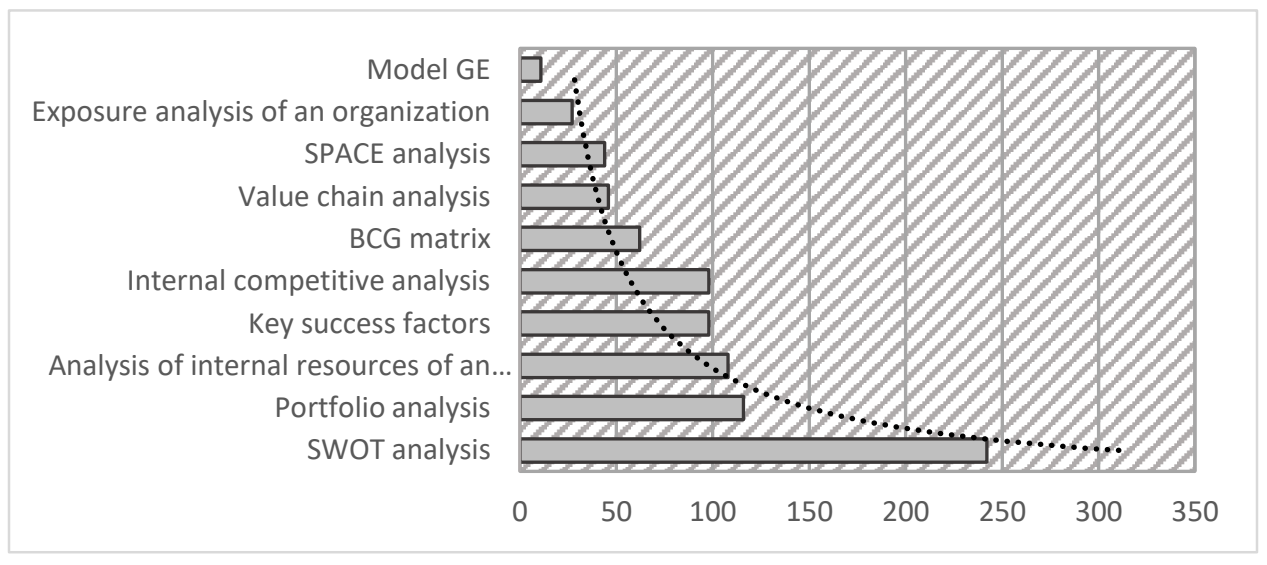

Fig. 3. Frequency of strategic analyses in the internal business environment

Source: Own research.

Frequency of strategic analyses in the external business environment illustrates the figure 4.

\section{Strategy clock \\ Industry driving forces analysis \\ Industry life cycle analysis \\ Interest group analysis}

Industry's economic characteristics analysis

Industry's attractiveness analysis

Scenarios (external business environment..

Strategic maps

STEP analysis

Industry competitive analysis (Porter's five...

Competitive analysis

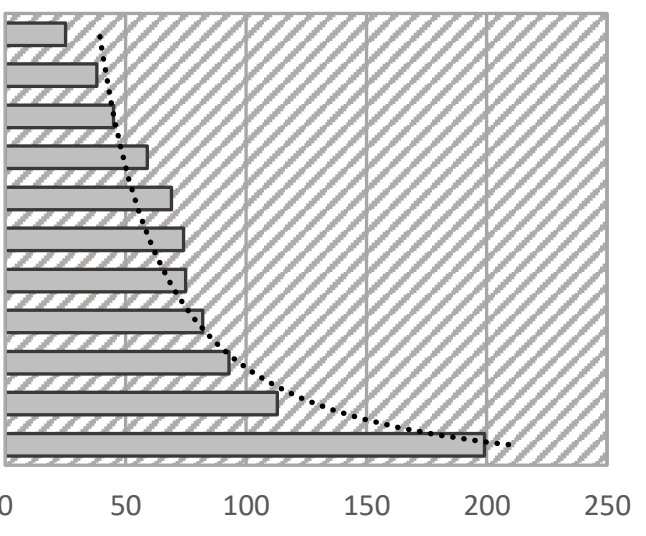

Fig. 4. Frequency of strategic analyses in the external business environment

Source: Own research. 
As regards the knowledge and use of external methods of a situation analysis (Fig. 4), the least used methods include: Strategy clock, industry driving forces analysis and industry life cycle analysis. On the opposite side, we find a competitive analysis - Porter's model which is a positive finding especially in the period when domestic and foreign competition is increasing. These analyses also include a STEP analysis which is an adequate supplement to the two above methods. The negative fact is that more than more than $60 \%$ companies are not aware of these methods, including their practical application in the business environment.

As regards internal analyses, dependence of development of a corporate strategy on the sector focus, size and scope / sphere of influence of an organization (Tab.1) was analysed together with the frequency of strategic methods. Dependence was only established in a value chain analysis with respect to sector differentiation of tested companies. This finding is fully consistent with the theory for development of a corporate strategy that states that value chain will be among the key tools for development of a corporate strategy in future. No statistically significant values were established in other internal analyses both in terms of size categorization of tested companies and their scope / sphere of influence. In accordance with the outputs of the solution, the second hypothesis is also rejected.

Table 1. Dependence of development of a corporate strategy on the sector focus, size and scope / sphere of influence - internal analyses

\begin{tabular}{|l|r|r|r|}
\hline \multicolumn{1}{|c|}{ Analysis } & $\begin{array}{c}\text { Company focus } \\
\text { p.value }\end{array}$ & $\begin{array}{c}\text { Company size } \\
\text { p.value }\end{array}$ & $\begin{array}{l}\text { Scope / sphere of } \\
\text { influence p.value }\end{array}$ \\
\hline SWOT analysis & 0.8921 & 0.4663 & 0.4305 \\
\hline Portfolio analysis & 0.3586 & 0.8461 & 0.1377 \\
\hline $\begin{array}{l}\text { Analysis of internal resources } \\
\text { of an organization }\end{array}$ & 0,3162 & 0.4976 & 0.5966 \\
\hline Key success factors & 0.9874 & 0.1927 & 0.2976 \\
\hline Internal competitive analysis & 0.3086 & 0.4195 & 0.9636 \\
\hline BCG matrix & 0.871 & 0.4078 & 0.9106 \\
\hline Value chain analysis & $\mathbf{0 . 0 0 8 4 2 8}$ & 0.1927 & 0.6386 \\
\hline SPACE analysis & 0.913 & 0.3004 & 0.887 \\
\hline Company's exposure analysis & 0.6613 & 0.9451 & 0.3936 \\
\hline GE model & 0.6139 & 0.7167 & 0.5219 \\
\hline
\end{tabular}

Source: Own research.

Table 2 illustrates dependence of development of a corporate strategy on the sector focus, size and scope of an organization in external analyses. An interest group analysis and industry driving forces analysis indicated statistically significant values only in terms of company size categorization. A lower level of dependence was identified in an industry driving forces analysis, namely the category of scope/sphere of influence of tested companies. The negative finding was that the Porter's model was absent, or an internal industry structure analysis considered as very important on a theoretical level and essential for creating a corporate strategy. 
Table 2 Dependence of development of a corporate strategy on the sector focus, size and scope / sphere of influence - external analyses

\begin{tabular}{|l|r|r|r|}
\hline \multicolumn{1}{|c|}{ Analysis } & $\begin{array}{c}\text { Company focus } \\
\text { p.value }\end{array}$ & $\begin{array}{c}\text { Company size } \\
\text { p.value }\end{array}$ & $\begin{array}{r}\text { Scope / sphere of } \\
\text { influence p.value }\end{array}$ \\
\hline Competitive analysis & 0.6514 & 0.1242 & 0.5069 \\
\hline $\begin{array}{l}\text { Industry competitive analysis (Porter's five } \\
\text { forces model) }\end{array}$ & 0.7713 & 0.671 & 0.6984 \\
\hline STEP analysis & 0.8112 & 0.3615 & 0.1917 \\
\hline Strategic maps & 0.198 & 0.437 & 0.7463 \\
\hline $\begin{array}{l}\text { Scenarios (external business environment } \\
\text { development prediction) }\end{array}$ & 0.429 & 0.6221 & 0.8786 \\
\hline Industry's attractiveness analysis & 0.1391 & 0.8971 & 0.903 \\
\hline Industry's economic characteristics analysis & 0.935 & 0.7879 & 0.2913 \\
\hline Interest group analysis & 0.8808 & $\mathbf{0 . 0 4 9 4 4}$ & 0.9808 \\
\hline Industry life cycle analysis & 0.5083 & 0.4595 & 0.1912 \\
\hline Industry driving forces analysis & 0.4083 & $\mathbf{0 . 0 1 2 1 9}$ & 0.09801 \\
\hline Strategic clock & 0.8145 & 0.3031 & 0.2803 \\
\hline
\end{tabular}

Source: Own research.

It is right to say that the research was conducted in a period of strong economic growth which could affect the approach and mind-set of managers. This fact does not necessarily indicate that tested companies do not address the key factors determining the internal structure of an industry, but the importance of those is decreased in a period promoting growth.

Unlike the evaluation results of each individual factor, the group evaluation of factors (Table 3) confirmed dependence of the technological and political and legal aspects in the manufacturing and industrial sector, and all aspects in the service sector.

Table 3. Expected impact of the business macro environment on the development of a corporate strategy and profitability

\begin{tabular}{|c|r|r|}
\hline Manufacturing and industrial sector & \multicolumn{1}{|c|}{ p value } & \multicolumn{1}{c|}{ chi-square } \\
\hline Social and cultural & 0.5791 & 4.7287 \\
\hline Technological & 0.04612 & 12.812 \\
\hline Economic & 0.06491 & 11.8708 \\
\hline Political and legal & 0.03092 & 13.887 \\
\hline Service sector & & 14.2751 \\
\hline Social and cultural & 0.02671 & 45.5452 \\
\hline Technological & 0.00000003647 & 37.4832 \\
\hline Economic & 0.000001417 & 35.4432 \\
\hline Political & 0.000003536 & \\
\hline
\end{tabular}

Source: Own research.

It can be concluded that the technical and technological aspect, including the innovation process, and the political and legal aspect are crucial for the manufacturing sector; a higher level of cohesion with the external environment was observed in the service sector as well as a direct impact of those factors on changes in the corporate strategy.

\section{Conclusion}

In accordance with the outputs from the solution, evidencing that more than $60 \%$ companies do not create vision and mission statements and a corporate strategy, the first hypothesis was rejected. It is alarming, but it can be rectified in the medium term. The 
participation of research organizations, including universities and public administration and regulatory authorities will be important to rectify this negative situation.

A prerequisite for efficient and effective strategic management is knowledge of situation analysis methods and tools where similar lack of knowledge and implementation in business practice was observed. Therefore, the second hypothesis expecting such knowledge and use in business practice by the majority of businesses, or managers was also rejected. Some internal as well as external methods show absolute lack of awareness. The average knowledge of those methods is app 50\%. There the managerial literacy is at a very low level and again, the key role must be played by research institutions and transfer of their knowledge into business practice.

\section{Suggestions for Practice}

In the last decade, the business environment has undergone some fundamental changes affecting all of its elements. This actual and ever more intensive trend involves system changes in the concept of strategic management. The most important changes are:

- Corporate strategy should not only be consistent with requirements of the local market, but it should consider the regional, national markets, and recently also international aspects of the globalized, or globalized market.

- Standard concept of strategy as a long-term fixed document loses its original purpose due to turbulent changes in the external business environment.

- Corporate strategy has recently become a document on various alternatives of approach and processes according to the specific business situation and this statement applies more to SMEs than larger businesses.

- Every organization should create a vision and mission statement as well as strategic goals. These fundamentals are important for establishing a company and relationships and expectations for behaviour in the workplace and a corporate culture, and for defining the position where the company should be visible in a certain period of time and what performance and financial figures should be achieved by the company. Their projection must ensure a flexible response to external environmental effects.

- The existence of a long-term development plan, or a corporate strategy provides the basis for business sustainability and efficiency and it can be referred to as the precondition for existence of a business. If absent, the business can lose its competitive advantage.

- Human resources are the essential attribute for competitive advantage and profitability of an organization; continuous and systematic training of senior managers on strategic management and decision making processes is a prerequisite for existence of a viable business.

\section{Acknowledgements}

This article was supported by the project "Stabilization and development of SME in rural areas", reg. No. TL01000349, the TACR Éta programme. 


\section{References}

1. M.E. Porter, Konkurenční strategie: metody pro analýzu odvětví a konkurentů [Competitive stratégy: methods for analysis of industry and competitors]. Prague: Victoria Publishing (1994)

2. R. Peterson, R. Rondstadt, A silent strength: Entrepreneurial know who. In paper presented to the 16th European Small Business Seminar (1987)

3. R. Sanchez, Strategic flexibility in product competition. Strategic Management Journal, 16, 135-159 (1995)

4. G. Rajdeep, P. Tansuhaj, Building Organizational Capabilities for Managing Economic Crisis: The Role of Market Orientation and Strategic Flexibilit. Journal of Marketing, 65(2), 67-80 (2001)

5. P.R. Krugman, M. Obstfeld, M.J. Melitz, International Economics: Theory and Policy, Harlow: Pearson Education Limited (2015)

6. G. Gibbs, Learning by doing a guide to teaching and learning methods. EMU Oxford Brookes University, UK (1988)

7. D.G.W. Birch, The Job Generation Process. MIT Program on Neighborhood and Regional Change (1979)

8. G. Gunderson, The Wealth Creators: An Entrepreneurial History of the United States. New York: Truman Talley Books, E. P. Dutton (1989)

9. J. Mugler, Podnikové hospodářství malých a středních podniků I [Business administration of small and medium enterprises I]. Plzeň: University of West Bohemia (2011)

10. C.E. Helfat, Dynamic capabilities: understanding strategic change in organizations. Malden: Blackwell (2007)

11. R.E. Miles, C.C. Snow, A.D. Meyer, Organizational strategy, structure, and process. Stanford, Calif: Stanford University Press (2008)

12. M. Augier, T.J. Teece, Understanding complex organization: the role of know-how, internal structure, and human behavior in the evolution of capabilities. Industrial and Corporate Change, 15(2), 395-416 (2006)

13. D.J. Teece, Strategy, Innovation and the Theory of the Firm. Northampton: Edward Elgar Publishing (2012)

14. V. Ambrosini, C. Bowman, What are Dynamic Capabilities and are They a Useful Construct in Strategic Management? International Journal of Management Review, 11(1), 29-49 (2009)

15. A. Kuuluvainen, Dynamic capabilitiesin the International Growth of Small and Medium-Sized Firms. Turku School of Economics: Uniprint (2011)

16. A. Lundström, L.A. Stevenson, Entrepreneurship Policy. Theory and Practice. New York: Springer (2005)

17. AMSP ČR [online], Available at: http://www.amsp.cz/10-pruzkum-amsp-cr-nazorypodnikatelu-na-moderni-metody (2017) 